\title{
LA PERSPECTIVA DE GÉNERO: EL DISCURSO de la Alta Consejería Presidencial para la Equidad de la Mujer*
}

Claudia Lugo Upegui ${ }^{* *}$ Patricia Herrera Kit ${ }^{* * *}$

\section{Resumen}

Desde finales de los años setenta el Estado colombiano inició el proceso de configuración de la institucionalidad dedicada a la protección de los derechos de las mujeres. Dicho proceso se ha caracterizado por una constante transformación de la estructura del mecanismo nacional y, a la vez, por los cambios en las prioridades que este ha puesto en la agenda nacional en relación con el adelanto de las mujeres. El presente artículo buscará analizar, a la luz del contenido de las exigencias y visiones internacionales en materia de los derechos de las mujeres, el ajuste institucional y el sustento de la transformación de la acción de la Consejería Presidencial para la Equidad de la Mujer (СРEM). Así, teniendo en cuenta las prioridades esbozadas en el referencial internacional, se pretende identificar los referenciales a partir de los cuales la CРEM ha venido impulsando la inclusión del tema de las mujeres en la agenda pública nacional.

Palabras clave: mecanismo nacional para el adelanto de las mujeres, referenciales de

* La versión preliminar del presente documento se presentó en el viıI Congreso Latinoamericano de Ciencia Política (alacip) que se llevó a cabo en la Pontificia Universidad Católica del Perú entre el 22 y 24 de julio de 2015.

** Maestría en Estudios Latinoamericanos, mención Política. Docente de la Facultad de Finanzas, Gobierno y Relaciones Internacionales de la Universidad Externado de Colombia, Bogotá (Colombia). [claudia.lugo@uexternado.edu.co].

*** Doctora en Estudios Políticos. Docente Investigadora de la Facultad de Finanzas, Gobierno y Relaciones Internacionales de la Universidad Externado de Colombia, Centro de Investigaciones y Proyectos Especiales (CIPE), Bogotá (Colombia). [patricia.herrera@uexternado.edu.co].

Recibido: 5/02/2017/ Modificado: 21/04/2017/ Aceptado: 01/06/2017.

Para citar este artículo

Lugo Upegui, C. y Herrera Kit, P. (2017). La perspectiva de género: el discurso de la Alta Consejería Presidencial para la Equidad de la Mujer. Opera, 21, pp. 157-181.

DOI: https://doi.org/10.18601/16578651.n21.09 
políticas públicas, derechos de las mujeres, acción pública.

\section{A GENDER PERSPECTIVE: THE PRESIDENTIAL COUNCIL FOR WOMEN'S EQUALITY DISCOURSE}

\section{Abstract}

Toward the end of the 1970s, the process of establishing an institutional framework dedicated to the protection of women's rights began in Colombia. This process has been characterized by a constant transformation of the national mechanism structure and, at the same time, by the changes in the priorities that said process has placed on the national agenda in relation to the empowerment of women. This article seeks to analyze, in light of the content of international pressures and visions regarding women's rights, the overall institutional adjustment and the related support for the transformation undertaken by the Presidential Council for Women's Equality (СРем). Accordingly, taking into account the priorities outlined in the international framework, it intends to identify the référentiel from which the СРЕм has been promoting the inclusion of women in the national public policy agenda.

Key words: National mechanism for the advancement of women, public policy référentiel, women's rights, public action.

Los resultados expuestos en el presente artículo constituyen los avances de una inves- tigación más amplia que surgió a partir de la preocupación de las autoras por la proliferación del uso de la noción de "perspectiva / enfoque de género" en las políticas nacionales, tanto las destinadas a las mujeres como las políticas sectoriales en Colombia, contrastada con la persistencia de prácticas que permiten inferir la inmutabilidad, o cuando menos la resistencia al cambio, de las lógicas propias de un orden de género en la sociedad nacional. Así, pese a la constatación de avances en la situación de las mujeres en algunos ámbitos, la función de las políticas públicas en tanto vehículo transformador de realidades sociales, en este caso las de las mujeres colombianas, no sugiere haber logrado aún de manera definitiva sus propósitos, al igual como sucede también en otras regiones del mundo. Como lo señala el Secretario General de las Naciones Unidas en su informe del 2014 dedicado al examen de la aplicación de la Declaración y Plataforma de Acción de Beijing, pese a los innegables avances "el progreso general ha sido inaceptablemente lento, con estancamientos, e incluso retrocesos, en algunos contextos. El cambio a favor de la igualdad entre los géneros no ha sido suficientemente profundo ni irreversible" (Secretario General, 2014, p. 6).

En este contexto, la reflexión en torno a las razones que explican los avances nacionales en materia de derechos de las mujeres adquiere relevancia, pues desde los ańos ochenta el país reporta acciones específicas en la materia, incluyendo la creación y permanente adecuación de la institucionalidad encargada de promover la inclusión de la perspectiva de género en el 
quehacer estatal ${ }^{1}$, la puesta en marcha de políticas para mujeres y una importante adecuación normativa. La investigación de la cual hace parte el resultado consignado en el presente artículo se propone explorar dos factores: las ideas, los valores a partir de los cuales se formulan las políticas, y, por otro lado, la capacidad institucional para poner en marcha políticas que transformen o incidan en la trasformación de las relaciones sociales, más allá de resolver necesidades de las mujeres o situaciones puntuales que conculquen sus derechos. Los dos factores están estrechamente relacionados pues sin un sustento transformador, sin un referente alternativo, la capacidad y la respuesta institucional no serán suficientes y las políticas seguirán el camino de lo que autoras como Guzmán Barcos y Montaño Virreira (2012) denominan la "solución política". En este caso, se hace alusión a respuestas focalizadas en las necesidades de mujeres especialmente vulnerables, sin afectar "los marcos de sentido tradicionales sobre los papeles de hombres y mujeres que sustentan el conjunto de las acciones de los gobiernos" (p. 16) y las relaciones sociales. $\mathrm{O}$, incluso, profundizarán los avances en la acción pública destinada a los problemas específicamente femeninos (Guzmán y Montaño, 2012).
En este orden de ideas, el artículo es un avance en la reflexión sobre las ideas que sugieren fundamentar la actuación nacional en materia de derechos de las mujeres. Su propósito es analizar, a la luz del contenido de las visiones internacionales en materia de protección de los derechos de las mujeres, el ajuste institucional y el sustento de la transformación de la acción de la Consejería Presidencial para la Equidad de la Mujer (СРEM) desde su creación hasta el 2014. Se pretende, por un lado, identificar las ideas que se materializan en temas que proyecta el discurso del sistema de las Naciones Unidas y el sistema regional de protección de los derechos de las mujeres. Y, por otro lado, con base en un recorrido por la consolidación de la respuesta colombiana, constatar el tipo de temas que conforman el discurso y, por tanto, el sentido de la actuación de la institucionalidad nacional prevista para el tema.

Así, aunque se reconozca el acervo de la reflexión de los estudios de género sobre la materialización de los derechos de las mujeres, el documento se ubica en el dominio del análisis de políticas públicas, disciplina que en su vertiente cognitiva destaca el valor cardinal que tienen las ideas en los procesos de formulación de las acciones públicas (Fontaine, 2016; Surel, 2011). A partir del análisis del contenido del

\footnotetext{
1 Sin contar los innumerables ajustes normativos adoptados desde la adopción de la Constitución de 1991, en su texto "Recorrido por las políticas públicas de equidad de género en Colombia y aproximación a la experiencia de participación femenina con miras a la construcción de escenarios locales", Ana Milena Montoya Ruiz presenta el siguiente recuento: en 1984 se expide, a través del CONPES 2109, la política nacional para la mujer campesina; en el año 1988 se adopta la política de hogares y madres comunitarias del Instituto Colombiano de Bienestar Familiar (ICBF); para el año 1992, fecha en la cual con la nueva Constitución se crea a través del Decreto presidencial 1878 la Consejería para la Mujer, la Juventud y la Familia (Puyana, 1998); por medio del conpes 2626 se adopta la política integral para mujeres; y con la Resolución 1531, la política de salud para las mujeres; en el año 1993, con el CONPES Social 23, se expide la política para el desarrollo de la mujer rural; y en 1997, con el CONPES 2941, se adopta la política de equidad y participación para las mujeres (2009, p. 308).
} 
discurso, se pretende identificar las prioridades temáticas del sistema internacional y nacional, sus encuentros y desencuentros. Lo anterior debido a que sus pronunciamientos consignan los referenciales que definen las pautas de acción en materia de protección de los derechos de las mujeres.

En un sentido similar a las preocupaciones epistemológicas de los enfoques cognitivos para los que las políticas públicas son las productoras de las visiones del mundo (PuelloSocarrás, 2007), también trabajos como los de Schmidt (2008) destacan el valor que tienen las ideas en el accionar público. Aunque inscrita en los supuestos neoinstitucionalistas, su propuesta de institucionalismo discursivo pretende avanzar hacia el análisis del cambio en el contenido de las políticas asociando las ideas, y el discurso que las transporta, con la agencia. De esta forma, la postura de Schmidt (2008) pone un acento que la aproxima a los análisis cognitivos de políticas públicas, en la función que tienen los valores, las normas y las ideas de los actores (Muller, 2005). En especial, los de los tomadores de decisión y de quienes inciden en la construcción de la acción pública, pues estos actores hacen parte de un determinado entramado social y deconstruyen y reconstruyen el mundo, en palabras de Muller (2006), desde una determinada comprensión de la realidad social. Pero también, los trabajos de Schmidt rescatan la agencia, pues el discurso no es descontextualizado y, en consecuencia, la comprensión de su capacidad de transformación está asociada con quién es el autor del discurso, cuándo, dónde y cómo lo pone en marcha. Este supuesto también lo asume Muller (2006) en sus trabajos del referencial, aunque en una dimensión distinta, cuando señala que la acción pública es resultado de la intervención de actores, de mediadores de políticas encargados de posesionar, traducir o acercar los distintos niveles de referencial que puedan gravitar en la sociedad en torno a un mismo tema. En palabras de este representante de análisis de referencial:

...elaborar una política pública se reduce a construir una representación, una imagen de la realidad sobre la cual se quiere intervenir. Es en referencia a esta imagen cognitiva que los actores van a organizar su percepción del sistema, confrontar sus soluciones y definir sus propuestas de acción: llamaremos este conjunto de imágenes "el referencial de la política pública" (pp. 97-98).

En este sentido, y dado el papel que las ideas juegan en el marco de los análisis cognitivos de políticas públicas, en el presente documento su caracterización se realizó a partir de la identificación de las temáticas que sugieren ser predominantes en el discurso elaborado en los espacios de producción de sentido de y para la acción en materia de los derechos de las mujeres. Con el apoyo del Atlas ti se llevó a cabo una revisión de documentos a través del análisis de discurso $(\mathrm{AD})^{2}$ que, en palabras

2 A partir de la distinción entre el análisis lingüístico (ALD) y no lingüístico del discurso (ANLD), Sayago sostiene que: "A menudo, se plantea la diferencia metodológica entre las estrategias cualitativas y las cuantitativas como un enfrentamiento de cosmovisiones o de paradigmas. [... Sin embargo, es posible asumir que las estrategias que se diseñan e implementan tanto desde una perspectiva como desde la otra se pueden complementar. Un ejemplo 
de Sayago (2013; 2014), no solo se concibe en tanto un campo de estudio caracterizado por la diversidad de corrientes y enfoques que a él se adscriben. Por el contrario, y de manera complementaria, puede ser utilizado como técnica que permite combinar el análisis cualitativo y cuantitativo, a la cual se acude, entre otros, por los requerimientos del estudio $(2013 ; 2014)$ que, en el presente caso, se circunscribe a la identificación de las temáticas que conforman los referenciales de la acción en materia de los derechos de las mujeres y cuyo contenido, convergencias y divergencias, se hacen manifiestos en los documentos escritos que fueron agrupados en tres grandes unidades: documentos académicos e institucionales; del sistema internacional y documentos nacionales.

La revisión del universo de documentos académicos e institucionales, expuesta en la primera sección, se hizo con base en el análisis de reportes cualitativos construidos sobre categorías definidas con el fin de aportar algunos elementos de contextualización sobre la evolución de la concepción de la acción en materia de derechos de las mujeres en el sistema internacional y nacional. El carácter introductorio de esta sección explica que no se pretenda aportar y abordar de manera pormenorizada dimensiones relevantes para los debates feministas. La elección de las categorías de equidad e igualdad se hizo en función de su uso recurrente en las políticas nacionales para mujeres; a su vez, los enfoques mujeres en el desarrollo (MED) y género en el desarrollo (GED) fueron escogidos debido a que estos, entre otros, guían los análisis que han influido en la práctica del desarrollo. Finalmente, se acude al concepto de género por su relevancia en la construcción del referencial de la acción en la materia.

En la segunda parte, con el fin de identificar las ideas presentes en el discurso internacional que movilizan la acción destinada a las mujeres, se analizaron reportes cuantitativos elaborados con base en 17 documentos del sistema de las Naciones Unidas y del sistema regional. Dichos documentos plasman, ya sea desde la perspectiva convencional o de plataformas de acción, los derroteros de la acción estatal en la materia; exponen el contenido de los debates regionales, como sucede en el caso de los documentos de los consensos regionales; y dan cuenta de las prioridades que, en términos de seguimiento al cumplimiento de las obligaciones internacionales, proyectan los informes periódicos formulados por la CEDAW para el país ${ }^{3}$.

de complementariedad es el uso del ALD como técnica de análisis, puesto que esta es una herramienta metodológica que puede formar parte de una estrategia de análisis cualitativa, de una cuantitativa o de una combinación de ambas" (2013, p. 8).

3 Plataforma de Beijing de 1995, cedaw, Convención de Belém do Pará, ocho documentos de los consensos de las conferencias regionales sobre la integración de la mujer en el desarrollo económico y social de América Latina y el Caribe (Conferencia de 1991 de Curazao, Mar de Plata de 1994, Santiago de Chile de 1997, Lima 2000, México 2004, Quito 2007, Brasilia 2010 y Santo Domingo 2013), la Declaración sobre empoderamiento económico y político de las mujeres de las Américas del 2012, y cinco informes de observaciones formuladas por el Comité de la CEDAW a los informes periódicos de Colombia. 
Con el propósito de identificar los temas que sustentan la acción emprendida por la CPEM, en la parte final serán expuestos los resultados del análisis de reportes cuantitativos y cualitativos obtenidos de la revisión de los documentos nacionales. Estos fueron subdivididos en: políticas en las que se identifica de manera explícita la participación de la $\mathrm{CPEM}^{4}$; sus informes al Congreso 5 , por último, a las instancias internacionales como la CEDAW y la Comisión Interamericana de Mujeres ${ }^{6}$.

\section{ALGUNAS CONSIDERACIONES DE CONTEXTO}

Desde finales de los años sesenta se puede empezar a hablar de las mujeres como una preocupación en el sistema internacional y, en especial, en los temas de desarrollo. Esta preocupación ha evolucionado desde diferentes enfoques dependiendo de la etapa o de la teoría desarrollista predominante. Desde el enfoque antipobreza, pasando por el del bienestar, la eficiencia, la equidad, el empoderamiento, la transversalización, las capacidades -en función de la clasificación que se privilegie así como el organismo internacional que se analice- se infiere que se ha dado un tránsito desde una perspectiva que identifica a las mujeres como un sujeto aislado, susceptible de ser incorporado en la economía de los países y al motor del desarrollo, hacia una visión más garantista de derechos atravesada por conceptos como la ciudadanía, igualdad y equidad que se preocupa cada vez más por las relaciones que se tejen en la sociedad alrededor y con los sujetos femeninos. Así, hoy se impone la visión que entiende a la mujer como parte de un entramado de relaciones que configuran la sociedad y que, al mismo tiempo, se constituyen en las oportunidades o restricciones que estas encuentran en su desarrollo como sujetos de derechos. Esta perspectiva se pre-

4 Informe de actividades de la Consejería Presidencial para la Juventud, la Mujer y la Familia (1991); Conpes 2626 de 1992, Política Social para los jóvenes y las mujeres; Conpes 2726 de 1994, Política de participación y equidad de la mujer; Mujer y poder, elementos para la discusión (СРEM, 1994); CONPEs 2941 de 1997, Avances y ajustes de la política de participación y equidad para las mujeres; Plan de Igualdad de oportunidades para las mujeres, Bases del Plan y Plan Básico 2000-2002 (сPEM, 1999); CONPes 3077 de 2000, Política Nacional para la construcción de paz y convivencia familiar - Haz paz; Plan estratégico para la defensa de los derechos de la mujer ante la justicia en Colombia (стем y Comunidad de Madrid, 2003); Mujeres constructoras de paz y desarrollo, una política nacional orientada a la paz, la equidad y la igualdad de oportunidades (2002); CONPES 140 de 2011, Modificación a CONPES social 91 de 2005 "Metas y estrategias de Colombia para el logro de los objetivos de desarrollo del milenio -2015”; CONPES 147 de 2012, Lineamientos para el desarrollo de una estrategia para la prevención del embazo en la adolescencia y la promoción de proyectos de vida para los niños, niñas, adolescentes y jóvenes en edades entre 6 y 19 años; CONPEs 3784 de 2013, Lineamientos de política pública para la prevención de riesgos, la protección y garantía de los derechos de las mujeres víctimas del conflicto armado; CONPES 161 de 2013, Equidad de género para las mujeres.

5 Se tuvieron en cuenta seis informes de gestión de la CPEM al Congreso de la República (1990-1994; 2009-2010; 2010-2011; 2011-2012; 2012-2013; 2013-2014).

6 Cuatro informes a la CIM $(2004,2006,2008,2010)$; tres informes a la CEDAW (informe conjunto II y III; informe iv e informe conjunto $\mathrm{V}-\mathrm{VI}$ ). 
gunta por las razones de la subordinación y pretende contribuir a superarlas con miras a tener una sociedad con mayor desarrollo, no solo económico, sino también con condiciones de igualdad para hombres y mujeres.

De manera general, las agencias internacionales han dividido este cambio de concepción del papel de la mujer en la sociedad, y en las maneras de diseñar la correspondiente acción, en dos momentos: el enfoque de mujeres en el desarrollo (MED), y su versión alternativa, el enfoque de género en el desarrollo (GED) (Moser, 1998). Según el PNUd,

...el MED (mujeres en el desarrollo), considera que el principal problema es la exclusión de las mujeres del proceso de desarrollo, pues con ello se está desperdiciando la mitad de los recursos humanos productivos. La estrategia propuesta es $[\ldots]$ integrar a las mujeres en los procesos vigentes de desarrollo, aunque sin cuestionar la esencia de los mismos. El énfasis está puesto en el papel productivo de las mujeres, entendiendo su subordinación por su exclusión del mercado. Se desarrollan así acciones destinadas a mejorar la productividad y la generación de ingresos de las mujeres (vistas de manera aislada), pero desde su rol tradicional, en ámbitos como la salud, la alimentación, y el cuidado de la familia (s.f., p. 5).

Por su parte, el enfoque GED

...plantea que el problema, más que la exclusión de las mujeres -como lo plantea el enfoque MED- son las relaciones desiguales de poder y las estructuras que producen esa desigualdad, y que impiden un desarrollo en condiciones de equidad. El énfasis se pone en las relaciones de poder entre hombres y mujeres y en la transformación, no solo de las condiciones de vida de las mujeres, sino también de su posición en la sociedad (PNUD, s.f., p. 5).
Un concepto que no puede perderse de vista en este proceso de consolidación de una nueva perspectiva de acción dirigida al reconocimiento e ingreso definitivo en la agenda internacional de la defensa de los derechos de las mujeres, es el género. La palabra género hace referencia a los comportamientos sociales de hombres y mujeres y a las reglas que rigen sus interacciones. Las construcciones sobre lo que se considera femenino o masculino son resultados históricos de lo que algunos llaman pactos y negociaciones sociales. $\mathrm{Y}$ esta serie de pactos, como lo resalta el feminismo, ha ubicado a las mujeres en una posición de subordinación (Guzmán, 2003; Cobo, 1995).

El género, como orden institucional, ha enmarcado las relaciones de hombres y mujeres no solo definiendo -a través de normas formales e informales- las concepciones y percepciones que cada sujeto tiene sobre sí mismo, sino también encuadrando las limitaciones y hasta sus aspiraciones. El género lleva implícito un sistema de poder que define el juego de dominio, subordinación que condiciona el desarrollo de los sujetos a lo largo de sus vidas. También lleva consigo una organización sexual del trabajo, espacios (públicos y privados) que condicionan lo que la sociedad considera propio, adecuado para lo femenino y lo masculino, para hombres y para mujeres (Guzmán, 2003; Cobo, 1995).

Es importante resaltar que al ser un resultado histórico, el género es también una estructura que no es estática, es rígida, pero no inamovible. En este sentido, se puede decir que este sistema de relaciones sociales ha cambiado en la historia en la búsqueda de una estructura social de relaciones e interacción de poder 
más igualitaria para los sexos. De otra parte, es importante aclarar que la palabra género en el sistema internacional se ha usado en un sentido práctico para denominar los proyectos, programas e investigaciones que tienen que ver o se refieren más concretamente a la mujer o a las mujeres. "Cada vez se habla más de la perspectiva de género; sin embargo, al analizar dicha perspectiva se constata que género se usa básicamente como sinónimo de sexo: la variable de género, el factor género, son nada menos que las mujeres" (Lamas, 1999, p. 148).

La lucha por lograr la igualdad ha sido una meta de los movimientos de mujeres y el feminismo que han puesto el tema en la agenda de discusión y proceder público. Así, se aboga por una igualdad concebida desde su principio más esencial: "hombres y mujeres son iguales en el sentido de que son humanamente equivalentes o equipolentes es decir de igual valor humano [...] La equivalencia humana en el sentido de capacidades, de poder, de voz propia y autonomía” (García Prince, 2008, p. 40). Esta igualdad se traduce en derechos y oportunidades para hombres y mujeres, libres de discriminación y que, a final de cuentas, garantizaría no solo que los ciudadanos fueran iguales en términos formales de la ley, sino que también pudieran ejercer esta igualdad que valore y proteja las diferencias identitarias y que reduzca y elimine las desigualdades.

Ahora bien, especialmente en América Latina, el uso de la palabra igualdad, ligada al género y a la mujer, es acompańada por la palabra de equidad pues, como resaltan algunas autoras, existe una resistencia a la palabra igualdad dado que en la región muchas veces se le ha entendido partiendo del hombre co- mo modelo humano y, por tanto, se ha creído que cuando se hace alusión a la igualdad se hace referencia a la igualación de hombres y mujeres (Facio, s.f.). En Colombia, la palabra equidad es de uso común, como un elemento que permite aclarar las intenciones de la acción pública, entendiendo que esta abarcaría un significado más amplio, en el sentido de que rescata la diferencia y un énfasis en la igualdad de oportunidades, que se traduce en una igualdad real y no solo formal. Sin embargo, y como lo señala Alda Facio, el uso de la palabra equidad tampoco ha significado un gran cambio en la aclaración del objetivo de la acción pública y en la consecución de la igualdad, quedando aquella solamente en una declaración de intención y en una aspiración más que realidad (Facio, s.f.).

\section{LA CONSTRUCCIÓN DE DISCURSOS INTERNACIONALES EN MATERIA DE GÉNERO}

El tema de los derechos de las mujeres no es nuevo en la agenda internacional. Las preocupaciones por las vulneraciones que se derivan de la persistencia de la discriminación en los distintos ámbitos, tanto de la vida pública como la privada, producto del prevaleciente orden de género, hacen parte del trabajo de las Naciones Unidas así como del sistema regional de protección de derechos humanos. Y la configuración de estándares internacionales, la realización de las sucesivas conferencias mundiales, acompańadas e impulsadas además por las crecientes tendencias de articulación e incidencia de las organizaciones y ONG fe- 
ministas en el ámbito internacional y en los nacionales (Álvarez, 1997), se han constituido en los espacios de construcción de sentidos compartidos, aunque no exentos de diferencias y debates. Estos encuentros y desencuentros confirman lo que Muller (2006) plantea en torno al concepto del referencial global ${ }^{7}$ pues para el autor, este

...no constituye una presentación perfectamente coherente del mundo. En efecto, los valores que lo componen son objetivo de conflictos [...]. El referencial global no es más que un consenso, pero delimita el campo intelectual en el seno del cual van a organizarse los conflictos sociales. El conjunto de valores y de las normas del referencial global conforma un sistema jerarquizado, lo que significa que en una época algunas normas van a prevalecer sobre otras (p. 101).

En este sentido, tanto las Naciones Unidas como la OEA se han configurado en dos arenas internacionales en las cuales se ha perfilado el referencial global sobre el tema de los derechos de las mujeres y ha sido agenciado por actores internacionales, estatales, no gubernamentales y de la sociedad civil global ${ }^{8}$. El sentido que articula estos diversos tipos de ideas en el denominado discurso de coordinación -compuesto por individuos y grupos que toman la palabra y participan en la formulación, la delimitación del contenido de las políticas y estrategias-, no es uniforme en el espacio internacional como tampoco en el tiempo (Schmitd, 2008). Y, si bien se comparten unos conceptos nucleares, otros emergen y desaparecen, reciben mayor o menor atención en momentos y contextos distintos. Esta constatación se deriva del análisis de 17 documentos internacionales, agrupados en tres bloques, como se expone en la figura 1, que si bien mantienen la misma estructura (unos considerandos o parte dogmática y una resolutiva) revelan variaciones en el acento que ponen en los diversos temas relacionados con el adelanto de las mujeres.

\section{FIGURA 1. GRUPOS DE DOCUMENTOS PARA EL ANÁLISIS DEL DISCURSO INTERNACIONAL}

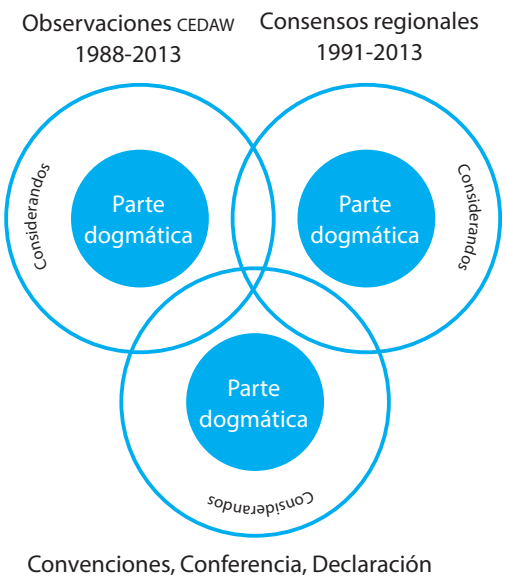

Fuente: elaboración propia.

\footnotetext{
7 El referencial global "está confirmado por un conjunto de valores fundamentales que constituyen las creencias básicas de una sociedad, así como por una serie de normas que permiten escoger entre varias conductas. Por ello, define la representación que una sociedad se hace de su relación con el mundo en un momento dado" (Muller, 2006, p. 100).

8 Sikkink y Keck catalogan la actividad desplegada por la sociedad civil global como redes transnacionales de cabildeo e influencia que, desde una lectura constructivista, giran o se sustentan en unas convicciones y valores compartidos (1999).
} 
Haciendo una lectura transversal, sin tener en cuenta la división entre la parte dogmática y resolutiva del universo de documentos analizados, se puede confirmar la relevancia que tienen para el sistema internacional, sin distinción entre espacios regionales y universales, los temas de educación, la violencia de género, la necesidad de adecuación normativa así como la salud de las mujeres. Asimismo, se destaca la relevancia que sugiere tener para el ámbito internacional el tema de la igualdad, el acceso a los cargos con poder de decisión, los derechos humanos y la situación de las niñas. De la misma forma, aparece el tema de la mujer indígena y las referencias a los mecanismos nacionales en tanto instancias encargadas de promover acciones destinadas al adelanto de las mujeres a nivel nacional; se hace referencia al tema de las mujeres rurales, el empleo y aparece con un importante énfasis la temática de las estadísticas e indicadores que miden en el nivel nacional e internacional las diversas dimensiones de las situaciones de las mujeres.

\section{Comparación entre los tres tipos de documentos}

Si esta misma lectura se hace teniendo en cuenta una distinción entre las tres familias de documentos (consensos regionales, observaciones de la CEDAW y las convenciones), los resultados empiezan a mostrar las primeras diferencias en relación con ciertos temas, consignadas en la tabla 1. Los temas fueron agrupados por

TABLA 1. PRESENCIA DE TEMAS EN LOS TRES TIPOS DE DOCUMENTOS

\begin{tabular}{|c|c|c|c|}
\hline & Consensos regionales & Observaciones de la CEDAw & $\begin{array}{c}\text { Convenciones, Conferencia } \\
\text { y Declaración }\end{array}$ \\
\hline $\begin{array}{l}\text { Primer nivel de } \\
\text { afinidad }\end{array}$ & \multicolumn{3}{|c|}{$\begin{array}{c}\text { Educación } \\
\text { Mujer rural } \\
\text { Acceso a cargos con poder de decisión }\end{array}$} \\
\hline \multirow{6}{*}{$\begin{array}{l}\text { Segundo nivel } \\
\text { de afinidad }\end{array}$} & Igualdad & & Igualdad \\
\hline & Mujer afro & Mujer afro & \\
\hline & Violencia de género & Violencia de género & \\
\hline & & Estadísticas e indicadores & Estadísticas e indicadores \\
\hline & Mecanismos nacionales & & Mecanismos nacionales \\
\hline & Salud & Salud & \\
\hline \multirow{7}{*}{$\begin{array}{l}\text { Tercer nivel de } \\
\text { afinidad }\end{array}$} & Acceso a tecnología & Mujer víctima de conflicto & Autonomía económica \\
\hline & Perspectiva de género & Acceso a la justicia & Niñas \\
\hline & Participación política & Capacitación de funcionarios & Derechos humanos \\
\hline & Mujer joven & Violencia intrafamiliar & Medio ambiente \\
\hline & Trabajo no remunerado & Estereotipos & Discriminación \\
\hline & & $\begin{array}{l}\text { Violencia en situaciones de } \\
\text { conflicto }\end{array}$ & Medios de comunicación \\
\hline & & & Estudios sobre la mujer \\
\hline
\end{tabular}

Fuente: elaboración propia a partir de los documentos priorizados para el análisis. 
niveles de afinidad, siendo el primero el que recoge los asuntos que sugieren ser los más presentes en los discursos contenidos en los tres grupos de documentos. A continuación, en el segundo nivel de afinidad se ubican los temas que sugieren ser sobresalientes en al menos dos grupos de documentos. Finalmente, en el tercer nivel de afinidad se ubican otros temas que, estando presentes en los tres grupos de documentos, sugieren recibir una prioridad distinta en los tres universos.

Es importante precisar que estos no son los únicos temas presentes en cada una de las familias de documentos, y tampoco se debe excluir la posibilidad de que asuntos que hacen parte del segundo nivel de afinidad para un grupo de documentos, no sean referidos en absoluto en los demás grupos. No obstante, la revisión del contenido de los documentos, permite inferir que algunos temas tienen más representatividad para los distintos ámbitos e instancias en las que se discuten. Así, por ejemplo:

- Es menos importante la presencia del tema de la mujer afro en los documentos del grupo de convenciones que, por el contrario, otorgan mayor atención a la mujer rural e indígena. A su vez este tema, analizado y puesto en el debate en arenas regionales como son los consensos regionales, denotan la atención que en los discursos de los actores regionales recibe la situación de las mujeres afro.

\section{FIGURA 2. REDES DE RELACIÓN DE CATEGORÍAS DE LAS TRES FAMILIAS DE DOCUMENTOS}

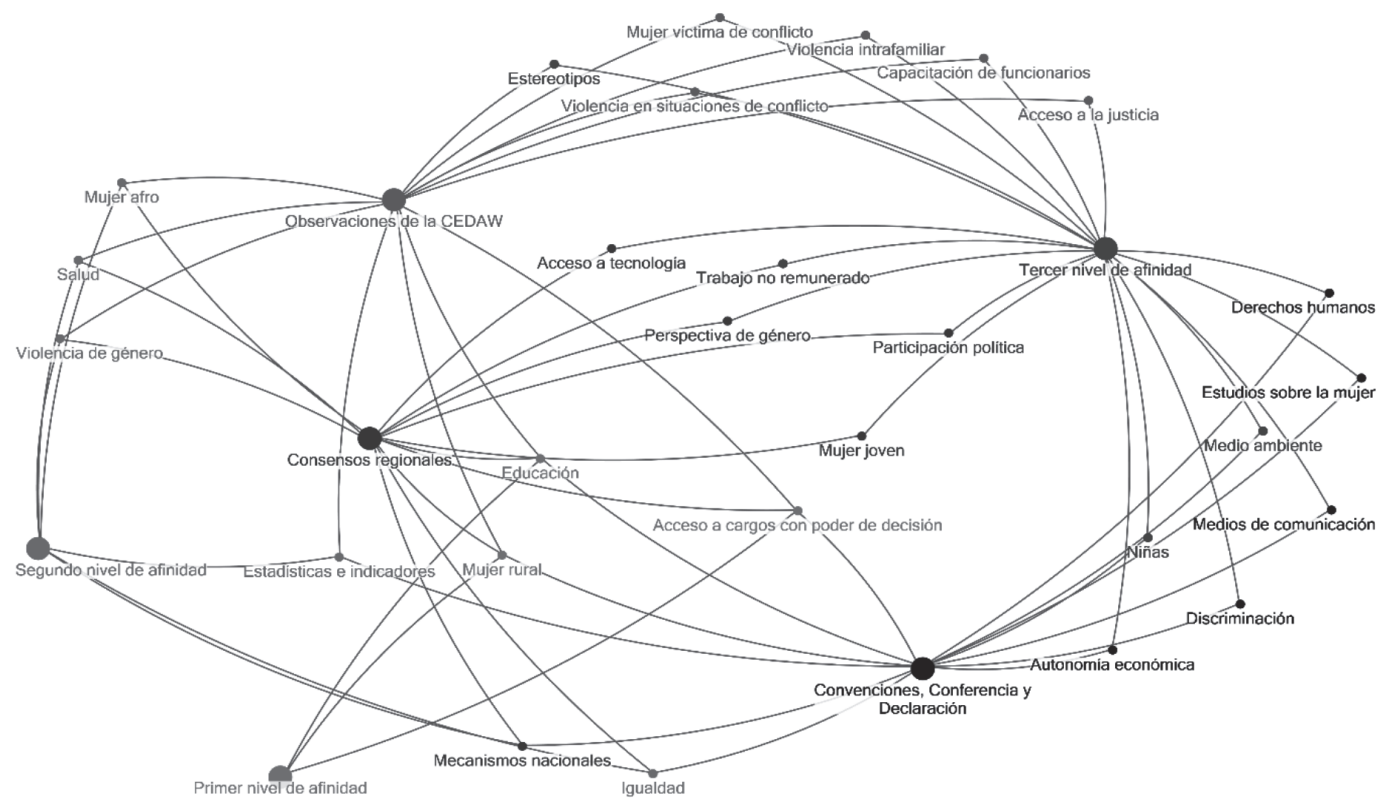

Fuente: elaborado a partir del análisis de los documentos. Las autoras agradecen al profesor Jesús Pardo su apoyo conceptual y técnico en el proceso de análisis de la información en el Atlas ti. 
- En las observaciones de la CEDAw para Colombia el tema de la violencia de género adquiere una dimensión más específica: la violencia en situaciones de conflicto, y denota la preocupación que el organismo de supervisión le otorga a los efectos diferenciales que tiene el conflicto en las mujeres colombianas. Así, si bien tanto los consensos regionales como los documentos del grupo de convenciones hacen referencia a los efectos que ellas padecen en la guerra, en el contenido de los documentos de las observaciones de la CEDAW, este tema resulta particularmente visible, pues analiza el caso puntual de la situación de la mujer en Colombia que no puede desligarse del contexto del conflicto que enfrenta el país.

Por otro lado, el análisis de la parte resolutiva o de recomendaciones del universo de los 17 documentos permite inferir que entre los temas que se insta que sean atendidos a través de acciones del Estado se hace un mayor énfasis en asuntos asociados con la educación y la salud; se insiste en la necesidad de la adecuación normativa que favorezca los cambios nacionales; la violencia de género; el acceso a los cargos con poder de decisión (incluso más que la sola participación política de las mujeres); la autonomía económica; las distintas acciones dirigidas a la protección de las nińas; la adecuación de los datos estadísticos, de indicadores y sistemas de información para que incluyan la perspectiva de género y faciliten la toma de decisiones; diversas acciones dirigidas a las mujeres indígenas, mujeres rurales $y$, por supuesto, el tema del fortalecimiento de los mecanismos nacionales y la inclusión de la perspectiva de género (figura 3). Estos hallazgos coinciden, en términos generales, con los temas contenidos en la tabla 1 , que sugieren que las recomendaciones emanadas de las instancias internacionales, en términos más generales, guardan relación entre los asuntos que suscitan mayor preocupación y el tipo de acción que instan adoptar a los Estados.

No obstante, una vez más, estas generalidades tienen dinámicas distintas al interior de cada uno de los grupos de documentos y también varían a lo largo de los años, pues las estrategias sugeridas para ser adelantadas en el nivel nacional cambian en su énfasis. Así, las recomendaciones de la CEDAw, expuestas en las observaciones a los informes de Colombia, hacen mayor énfasis en las realidades particulares de la situación de las mujeres en el país, muy asociadas con el contexto del conflicto armado y el tipo de respuesta que frente a esta realidad ha adelantado o ajustado el Estado. Lo anterior explica el acento que se le hace a temas como la atención a víctimas de violencias, resaltando la preocupación por la coordinación interinstitucional, el acceso a la protección y a la justicia, y la capacitación de funcionarios encargados de atender a las mujeres víctimas de los distintos tipos de violencia de género, haciendo énfasis en la situación de mujeres indígenas y rurales, derivada tanto del conflicto como de las situaciones cotidianas dada la persistencia de estereotipos.

Por su parte, en los documentos de convenciones las estrategias de acción están inscritas en las prioridades y líneas de acción previstas en la Declaración y Plan de Acción de Beijing. Los consensos regionales comparten 
FIGURA 3. TEMAS CON MAYOR PRESENCIA EN LAS RECOMENDACIONES Y LÍNEAS DE ACCIÓN EN EL UNIVERSO DE DOCUMENTOS ANALIZADOS

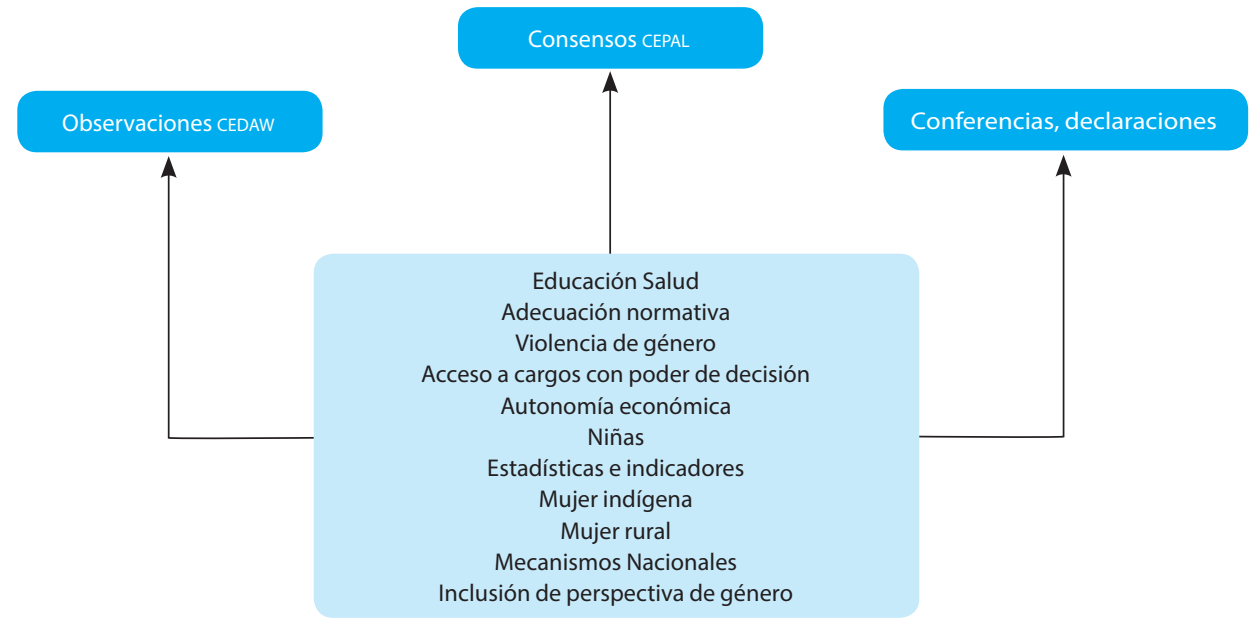

Fuente: elaboración propia a partir de los documentos priorizados para el análisis.

con las otras dos familias de documentos el énfasis en cuatro temas: salud, educación, adecuación normativa y generación de estadísticas, indicadores y sistemas de información con perspectiva de género, pero, adicionalmente, hacen énfasis en los temas de la mujer joven, acceso a la tecnología, las mujeres afro y la participación política.

De esta forma, si bien la figura 4 no expone la totalidad de temáticas abordadas en cada familia de documentos, permite constatar que al comparar los temas que aparecen con mayor acento en los tres ámbitos, se puede identificar una similitud en prioridades en asuntos como la educación, la salud, la adecuación normativa y las estadísticas e indicadores (contenido en el ovalo central de la ilustración). Pero, al mismo tiempo, cada uno de los espacios sugiere otorgar relevancia distinta a otros temas que tradicionalmente se asocian con el adelanto de la mujer. Estos temas se agrupan en los rec- tángulos que muestran que las prioridades en el segundo, al igual que en el tercer nivel de afinidad, varían en los tres tipos de documentos. En otras palabras, si bien muchos de los temas aparecen en los tres universos de documentos, lo que configura las afinidades, la prioridad con la que son abordados varían. Esta constatación explica el contenido diverso de los dos niveles de afinidad restantes, que se resaltan visualmente en la figura 4.

Los hallazgos expuestos hasta este punto ofrecen elementos para confirmar que, si bien hay un discurso general sobre el contenido y alcance de las acciones para el adelanto de las mujeres, las prioridades, o el énfasis en algunos de sus componentes, frentes o medios de acción varían a lo largo del tiempo, de los espacios y actores que conforman el debate y la construcción del discurso en la materia. Esto, leído a la luz de la construcción de referenciales, reitera que las ideas, los valores con base en los cuales 


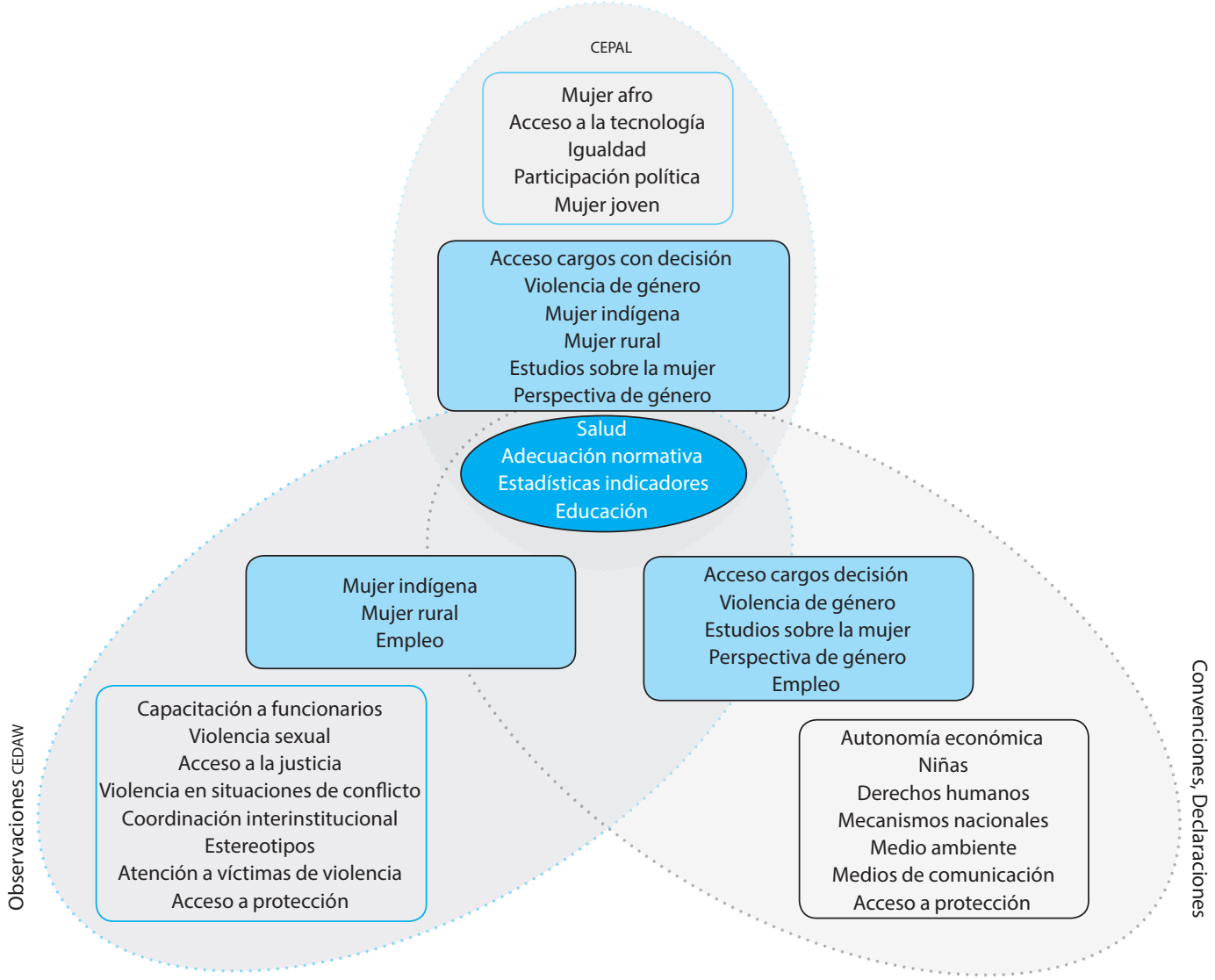

Fuente: elaboración propia a partir de los documentos priorizados para el análisis.

se delimita la acción pública son resultado de un proceso de construcción social, producto de conflictos, tensiones y posturas de diversos actores intervinientes.

\section{EL DISCURSO NACIONAL EN MATERIA DE GÉNERO}

La configuración de la acción pública de la CPEM frente a los derechos de las mujeres hace explícitos los debates en torno a la comprensión del papel de las mujeres en la sociedad nacional que marca, a su vez, la forma de intervenir sobre las realidades que restringen su participación en ella. Dicha intervención retoma de manera particular las discusiones y prioridades que tanto en temas como en formas de actuación delimita el debate internacional. En consecuencia, esta parte del documento busca constatar cómo, desde los años noventa hasta el presente, se han configurado la visión y las 
formas de intervención de la entidad encargada del adelanto de la mujer en Colombia. Con este propósito se analizan los decretos que han creado y transformado la estructura de la actual Consejería Presidencial para la Equidad de la Mujer (СРEM). Asimismo, y sin desconocer la amplitud de acciones públicas que aportan al goce de los derechos de las mujeres, se analizan algunas de las políticas en cuya formulación participó directamente la Consejería.

De manera preliminar se puede constatar que la Consejería ha sido objeto de numerosas transformaciones. Como lo consigna la tabla 2, la CPEM se ha reformado en algunas oportunidades en forma y, en otras, en fondo. Su perfil, en especial en los primeros años de existencia, sugiere haber estado enfocado prioritariamente en la asesoría, la supervisión de ejecución, el seguimiento de políticas, los estudios para la toma de decisión, la difusión y promoción, la gestión de recursos de cooperación, sustrayéndose en este sentido de las tensiones que registran los mecanismos nacionales en América Latina entre las estrategias de transversalización de género y la ejecución directa de políticas y programas (Guzmán, 2001).

A partir de mediados de los años noventa, cuando la Consejería se trasformó en la Dirección Nacional para la Equidad de las Mujeres, la entidad incursiona en este debate pues además de la formulación y ejecución de programas específicos en materia de mujeres, sus funciones comienzan a integrar actividades de inclusión de la perspectiva de género en políticas.

Esta transformación de funciones también está acompañada de un cambio de visión. Así, el primer informe de la Consejería en
1991 centra su atención en grupos vulnerables, incluyendo en ellos a las mujeres, y anuncia, en un contexto caracterizado por la crisis económica que atraviesa América Latina, la presencia de la ola de reformas neoliberales y de la Asamblea Constituyente de 1991, que se aparta de perspectivas asistencialistas. Estos dos elementos -atención a grupos vulnerables y el rechazo al asistencialismo- resultan interesantes como elementos de reflexión si se analizan en su contexto: la primera Consejería desarrolló su trabajo en un gobierno que en su Plan de Desarrollo, entre otras,

...enfatiza la solución de los problemas de los grupos más vulnerables en los campos de salud, educación y protección social. El examen de la evolución de la política social en Colombia y en otros países indica que ella es un instrumento muy poderoso para afectar las condiciones de equidad y bienestar de la población. En consecuencia, la política social, en lugar de plantear soluciones puntuales y asistenciales, debe establecerse como una estrategia de largo plazo. [...] La conciliación entre gasto social y crecimiento, que antes parecía imposible, es una de las características centrales de este Plan (DNP, 1991).

Las referencias que se hacen al concepto de asistencialismo en estos primeros años reiteran su uso ambiguo, y la justificación de cada nueva acción de gobierno de turno en materia de género evoca el carácter asistencialista de las estrategias o políticas concebidas por sus predecesores. Así, la comprensión de este concepto sugiere oscilar entre la necesidad de suprimir programas cuya puesta en marcha no exige como contrapartida esfuerzo alguno de las comunidades vulnerables (CPEM, 1991, 
TABLA 2. EVOLUCIÓN INSTITUCIONAL Y ALCANCE DE FUNCIONES DE LA CONSEJERÍA PRESIDENCIAL PARA LA EQUIDAD DE LA MUJER, 1990-2014

\begin{tabular}{|c|c|c|c|c|c|c|}
\hline $\begin{array}{l}\text { Asesoría, supervisión de } \\
\text { ejecución, seguimiento } \\
\text { de políticas, estudios pa- } \\
\text { ra la toma de decisión, } \\
\text { difusión, promoción, } \\
\text { gestión de recursos de } \\
\text { cooperación }\end{array}$ & & \multicolumn{5}{|c|}{$\begin{array}{l}\text { Promoción de acciones, impulso de incorporación de la perspectiva de } \\
\text { género, formulación y ejecución de programas, fortalecimiento de organi- } \\
\text { zaciones de mujeres, apoyo y asesoría, canalizar recursos de cooperación, } \\
\text { coordinación de espacios y actividades }\end{array}$} \\
\hline GAVIRIA & \multicolumn{3}{|c|}{ SAMPER } & \multicolumn{3}{|c|}{ PASTRANA } \\
\hline Decreto 1878 de 1990 & $\begin{array}{l}\text { Decreto } \\
2055 \\
\text { de } 1994\end{array}$ & $\begin{array}{l}\text { Ley } 188 \\
\text { de } 1995\end{array}$ & $\begin{array}{c}\text { Deceto } 1440 \\
\text { de } 1995\end{array}$ & $\begin{array}{l}\text { Decreto } \\
1182 \\
\text { de } 1999\end{array}$ & $\begin{array}{l}\text { Decreto } 2200 \\
\text { de } 1999\end{array}$ & $\begin{array}{l}\text { Decreto } \\
127 \text { de } \\
2001\end{array}$ \\
\hline $\begin{array}{l}\text { Consejería Presidencial } \\
\text { para la Juventud, la } \\
\text { Mujer y la Familia }\end{array}$ & $\begin{array}{c}\text { Comisión } \\
\text { Asesora para } \\
\text { la equidad } \\
\text { y la partici- } \\
\text { pación de la } \\
\text { mujer }\end{array}$ & $\begin{array}{l}\text { Dirección } \\
\text { Nacional } \\
\text { para la } \\
\text { equidad } \\
\text { de las } \\
\text { mujeres }\end{array}$ & $\begin{array}{c}\text { Dirección Na- } \\
\text { cional para la } \\
\text { equidad de las } \\
\text { mujeres }\end{array}$ & $\begin{array}{l}\text { Consejería } \\
\text { Presiden- } \\
\text { cial para la } \\
\text { equidad de } \\
\text { la mujer }\end{array}$ & $\begin{array}{l}\text { Ampliación } \\
\text { de } \\
\text { funciones del } \\
\text { Decreto } 1182 \\
\text { de } 1999\end{array}$ & $\begin{array}{c}\text { Consejería } \\
\text { Presiden- } \\
\text { cial para la } \\
\text { Mujer }\end{array}$ \\
\hline
\end{tabular}

Fuente: elaboración propia a partir de los decretos enumerados en la tabla.

p. 16), y la comprensión de programas asistenciales para mujeres entendidos como los que conciben los problemas de esta población de manera diferenciada e independiente de la sociedad nacional (CONPEs 2626, 1992).

La referencia que hace el CONPES $2626 \mathrm{de}$ 1992 a los problemas de las mujeres abre también un espacio para hacer mención, aunque por ahora preliminar, del sentido que inspira la respuesta estatal en materia de derechos de las mujeres, pues este documento puede ser inscrito en la lógica del discurso MED, que para la época ya se estaba cuestionando en el sistema internacional. El abordaje de la situación de la mujer a través de acciones que resolvieran sus necesidades prácticas y que, a la vez, las hicieran partícipes de la fuerza productiva de la economía, aparecen una y otra vez a lo largo del primer decenio de existencia de la Consejería. Sin embargo, no se puede desconocer que, de manera simultánea, se empieza a hacer el re- conocimiento de la existencia de relaciones de subordinación y demás elementos propios del enfoque GED. Esto pone en evidencia la elasticidad del discurso nacional que permite la cohabitación de distintos enfoques en las partes declarativas de sus políticas que, no obstante, no siempre se logran traducir en acciones que apunten a las necesidades estratégicas de las mujeres (Peláez, 2001).

Otro concepto que aparece de manera reiterada y prematura en el discurso es el de la coordinación interinstitucional que, como se mencionó, también resulta relevante en las recomendaciones que el Comité de la CEDAW le hace Colombia. Desde los primeros documentos producidos por la Consejería se hace referencia a una respuesta estatal que adolece de problemas de articulación entre sus políticas sectoriales, consideración que, entre otros, podría explicar la temprana inclusión en las funciones de la Consejería de las actividades de 
Asesoría, incorporación de persectiva de género, seguimiento al cumplimiento de obligaciones internacionales, impulso de estudios en materia de género, iniciativa legistativa, fortalecimiento de organizaciones de mujeres, canalizar recursos de coo-

Coordinación, diseño de lineamientos, seguimiento peración, apoyar diseño de políticas

\section{URIBE}

Decreto 519

de 2003

Consejería

Presidencial

para la Mujer

\begin{tabular}{c|} 
Decreto 3445 \\
de 2010 \\
Alta Consejería \\
Presidencial para \\
la Equidad de la \\
Mujer
\end{tabular}

C

Decreto 1649 de 2014

Consejería Presidencial para la Equidad de la Mujer
SANTOS

\section{Decreto 1930 de 2013}

Adopta la Política Nacional de Equidad de Género y crea la Comisión Intersectorial para su implementación impulso para la incorporación de la perspectiva de género en la gestión de entidades públicas del nivel nacional y territorial.

Como lo exponen la tabla 3 y la figura 5, a partir de una revisión preliminar de algunos de los CONPEs, tal inclusión de la perspectiva de género, como una estrategia de acción del Estado, se ha hecho operativa de diversas formas, partiendo, en todo caso, de la lógica de intervención intersectorial pues los documentos convocan competencias de diversas entidades y sectores de la acción pública.

En cualquiera de las modalidades privilegiadas para la operacionalización de la inclusión de la perspectiva de género, que en los últimos documentos sugiere transformarse en inclusión del enfoque de género, el tema de la coordinación resulta cardinal. Esta constatación, forzosamente y desde temprano, pone a la Consejería y al Estado de cara a sus capa- cidades de generar respuestas intersectoriales coordinadas.

Como lo muestra la tabla 3, el concepto de la coordinación aparece desde el primer CONPES de 1992, pero, y teniendo en cuenta que esta es una función que la Consejería asume hacia mediados de los años noventa, su presencia va en aumento para convertirse en un tema determinante hacia la época del primer Gobierno del presidente Santos, momento en el que también se puede constatar una interesante transformación en la lógica de la formulación de las políticas que tiende a reconocer una mayor complejización en temas, sujetos (mujer rural, indígena, LGTBI, mayor, joven, desplazada, afro, víctima del conflicto, presidiaria, defensora de derechos humanos, rom, con discapacidad, entre otras), dimensiones y actores. 
TABLA 3. CONTENIDO DE LOS CONPES Y POLÍTICAS

\begin{tabular}{|c|c|c|c|c|}
\hline GAVIRIA & \multicolumn{2}{|c|}{ SAMPER } & \multicolumn{2}{|c|}{ PASTRANA } \\
\hline CONPES 2626 de 1992 & $\begin{array}{c}\text { CONPES } 2726 \\
\text { de } 1994\end{array}$ & CONPES 2941 de 1997 & $\begin{array}{c}\text { Plan de Igualdad } \\
1999\end{array}$ & CONPES 3077 de 2000 \\
\hline $\begin{array}{l}\text { Política social para los } \\
\text { jovenes y las mujeres }\end{array}$ & $\begin{array}{l}\text { Política de } \\
\text { participación } \\
\text { y equidad de } \\
\text { para la mujer }\end{array}$ & $\begin{array}{l}\text { Avance y ajustes } \\
\text { de la Política de } \\
\text { Participación y } \\
\text { Equidad } \\
\text { para las Mujeres }\end{array}$ & $\begin{array}{l}\text { Bases del plan } \\
\text { de igualdad de } \\
\text { oportunidades }\end{array}$ & $\begin{array}{c}\text { Política para la } \\
\text { construcción de paz y } \\
\text { convivencia familiar - } \\
\text { haz paz }\end{array}$ \\
\hline 1. Desarrollo Humano & \multirow{2}{*}{$\begin{array}{l}\text { Una cultura } \\
\text { de equidad } \\
\text { entre mujeres } \\
\text { y hombres }\end{array}$} & \multirow{2}{*}{$\begin{array}{l}\text { A. Equidad } \\
\text { de género, } \\
\text { componente básico } \\
\text { de la equidad social }\end{array}$} & $\begin{array}{l}\text { 1. Trabajo y } \\
\text { generación de } \\
\text { ingresos }\end{array}$ & \multirow{3}{*}{$\begin{array}{l}\text { 1. Prevención de los } \\
\text { factores que originan y } \\
\text { mantienen la repuesta en } \\
\text { los espacios cotidanos }\end{array}$} \\
\hline a. Educación & & & \multirow{2}{*}{$\begin{array}{l}\text { 2. Salud, salud } \\
\text { reproductiva y } \\
\text { seguridad en } \\
\text { salud }\end{array}$} & \\
\hline b. Salud Integral & \multirow[t]{2}{*}{$\begin{array}{l}\text { Participación } \\
\text { en el mercado } \\
\text { laboral }\end{array}$} & $\begin{array}{l}\text { 1. Cultura de } \\
\text { equidad como } \\
\text { estrategia }\end{array}$ & & \\
\hline $\begin{array}{l}\text { c. Infraestructura Social } \\
\text { de Apoyo }\end{array}$ & & $\begin{array}{l}\text { 2. Estrategia de } \\
\text { protección legal } \\
\text { y derechos de las } \\
\text { mujeres }\end{array}$ & 3. Educación & \multirow{4}{*}{$\begin{array}{l}\text { 2. Vigilancia y detección } \\
\text { temprana de la utilización } \\
\text { de la violencia como } \\
\text { forma de relación y de } \\
\text { resolución del conflicto } \\
\text { en el hogar }\end{array}$} \\
\hline $\begin{array}{l}\text { d. Hábitat y Medio } \\
\text { Ambiente }\end{array}$ & \multirow{2}{*}{$\begin{array}{l}\text { Salud integral } \\
\text { para las } \\
\text { mujeres }\end{array}$} & $\begin{array}{l}\text { 3. Estrategia de } \\
\text { institucionalización }\end{array}$ & $\begin{array}{l}\text { 4. Vivienda y } \\
\text { hábitat }\end{array}$ & \\
\hline $\begin{array}{l}\text { e. Violencia Intra y } \\
\text { Extrafamiliar }\end{array}$ & & $\begin{array}{l}\text { B. Para el logro de la } \\
\text { eficiencia economía }\end{array}$ & \multirow{2}{*}{$\begin{array}{l}\text { 5. Participación } \\
\text { en la adopción de } \\
\text { decisiones }\end{array}$} & \\
\hline $\begin{array}{l}\text { 2. Desarrollo Productivo y } \\
\text { Apertura Económica }\end{array}$ & \multirow[t]{2}{*}{$\begin{array}{l}\text { Protección } \\
\text { legal }\end{array}$} & $\begin{array}{l}\text { 1. Estrategia de } \\
\text { empleo productivo }\end{array}$ & & \\
\hline $\begin{array}{l}\text { 3. Participación y } \\
\text { Organización }\end{array}$ & & $\begin{array}{l}\text { 2. Estrategia de } \\
\text { acceso a espacios } \\
\text { de poder y toma de } \\
\text { decisiones }\end{array}$ & $\begin{array}{l}\text { 6. Violencia contra } \\
\text { las mujeres }\end{array}$ & \multirow{3}{*}{$\begin{array}{l}\text { 3. Atención de las } \\
\text { personas y familias con } \\
\text { episodios de violencia } \\
\text { y maltrato infantil y } \\
\text { atención de agresores } \\
\text { de violencia doméstica y } \\
\text { maltrato y abuso sexual } \\
\text { infantil }\end{array}$} \\
\hline $\begin{array}{l}\text { 4, Cambo Cultural y } \\
\text { Jurídico }\end{array}$ & \multirow{2}{*}{$\begin{array}{l}\text { Mejorarlas } \\
\text { condiciones } \\
\text { para el trabajo } \\
\text { doméstico }\end{array}$} & \multirow{2}{*}{$\begin{array}{l}\text { 3. Estrategia para } \\
\text { el logro de la } \\
\text { conviviencia pacífica }\end{array}$} & $\begin{array}{l}\text { 7. Mujer y } \\
\text { conflicto armado }\end{array}$ & \\
\hline $\begin{array}{l}\text { 5. Desarrollo de la } \\
\text { Capacidad Institucional }\end{array}$ & & & 8. Mujer rural & \\
\hline
\end{tabular}

Fuente: elaboración propia de las autoras a partir de los documentos CONPES anunciados en la tabla.

Además de las especificidades previamente constatadas, y en comparación con los temas que con mayor énfasis se abordan en los discursos internacionales, los asuntos que se registran con más acento a lo largo de los documentos CONPES y de las políticas analizados son: violencia intrafamiliar; referencia a las mujeres víctimas del conflicto armado, en especial a partir de 1999; al igual que en el sistema internacional, se da una especial prio- 


\begin{tabular}{|c|c|c|c|}
\hline URIBE & \multicolumn{3}{|c|}{ SANTOS } \\
\hline 2003 & CONPES 147 de 2012 & CONPES 3S4 de 2013 & CONPES 161 de 2013 \\
\hline $\begin{array}{l}\text { Mujeres constructoras } \\
\text { de paz }\end{array}$ & $\begin{array}{l}\text { Prevención del } \\
\text { embarazo }\end{array}$ & $\begin{array}{l}\text { Mujeres víctimas del } \\
\text { conflicto armado }\end{array}$ & $\begin{array}{c}\text { Política equidad de género } \\
\text { para las mujeres }\end{array}$ \\
\hline \multirow{2}{*}{$\begin{array}{l}\text { Empleo y Desarrollo } \\
\text { empresarial de las } \\
\text { mujeres. }\end{array}$} & \multirow[t]{2}{*}{ 1. Intersectorialidad } & \multirow{3}{*}{$\begin{array}{l}\text { 1. Generar y fortalecer } \\
\text { estrategias de prevención } \\
\text { de riesgos y vulneraciones, } \\
\text { protección de los derechos } \\
\text { de las mujeres, y garantías } \\
\text { de no repetición }\end{array}$} & $\begin{array}{l}\text { Transformación Cultural y } \\
\text { Construcción de paz }\end{array}$ \\
\hline & & & $\begin{array}{l}\text { Autonomía económica y } \\
\text { acceso a activos }\end{array}$ \\
\hline Educación & $\begin{array}{l}\text { 2. Desarrollo humano y } \\
\text { proyecto de vida }\end{array}$ & & \multirow[t]{2}{*}{$\begin{array}{l}\text { Participación en escenarios de } \\
\text { poder y toma de decisiones }\end{array}$} \\
\hline $\begin{array}{l}\text { Salud sexual reproductiva } \\
\text { y seguridad en salud }\end{array}$ & & \multirow{3}{*}{$\begin{array}{l}\text { 2. Promover el ejercicio de } \\
\text { los derechos ciudadanos } \\
\text { de las mujeres víctimas } \\
\text { en los distintos entornos } \\
\text { socioculturales }\end{array}$} & \\
\hline $\begin{array}{l}\text { Violencias contra las } \\
\text { mujeres }\end{array}$ & $\begin{array}{l}\text { 3. Oferta de servicios } \\
\text { en Educación Sexual, } \\
\text { Salud Sexual y } \\
\text { Reproductiva y DSR }\end{array}$ & & $\begin{array}{l}\text { Salud y Derechos Sexuales y } \\
\text { Reproductivos }\end{array}$ \\
\hline \multirow{2}{*}{$\begin{array}{l}\text { Participación de las } \\
\text { mujeres en la política y } \\
\text { en la toma de decisiones }\end{array}$} & & & \multirow[t]{2}{*}{$\begin{array}{l}\text { Enfoque de Género en la } \\
\text { Educación }\end{array}$} \\
\hline & \multirow[t]{3}{*}{$\begin{array}{l}\text { 4. Monitoreo, } \\
\text { Seguimiento, } \\
\text { Evaluación y Gestión } \\
\text { del Conocimiento }\end{array}$} & \multirow[t]{3}{*}{$\begin{array}{l}\text { 3. Fortalecer la articulación } \\
\text { institucional mujeres } \\
\text { víctimas del conflicto } \\
\text { armado }\end{array}$} & \\
\hline Mujer rural & & & \multirow[t]{2}{*}{$\begin{array}{l}\text { Plan para garantizar una vida } \\
\text { libre de violencias }\end{array}$} \\
\hline Niñas & & & \\
\hline
\end{tabular}

ridad al tema de la educación; embarazo en adolescentes pues se cuenta con una política especial en la materia. De la misma manera, se hace énfasis en el tema de la salud, y sobresale la preocupación por la coordinación interinstitucional. Dado el impacto de la violencia de género y la violencia en contexto de conflicto, se destaca el tema de la atención a sus víctimas; asimismo, aparece la dupla de participación política y de acceso a los cargos con poder de decisión. 
FIGURA 5. ESTRATEGIAS DE INTERVENCIÓN EN MATERIA DE GÉNERO

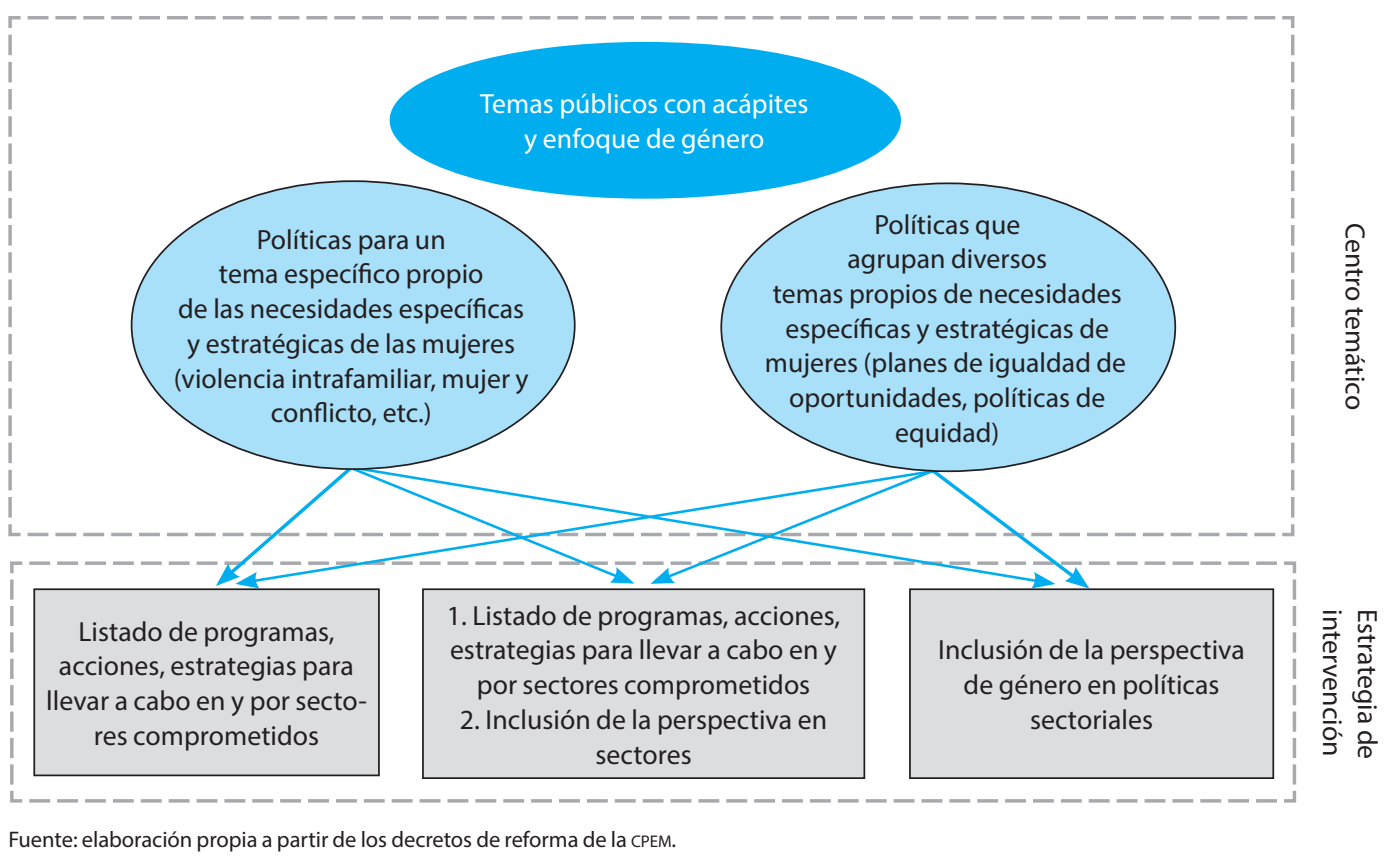

\section{CONCLUSIONES}

A lo largo del documento se han venido incluyendo, a la par con la exposición del análisis, algunos de los corolarios que se pueden desprender de los hallazgos que arrojó la revisión de los documentos internacionales y nacionales. Y, a manera de conclusión, vale la pena plantear algunas reflexiones globales.

La revisión de los documentos internacionales y nacionales relativos a los derechos de las mujeres permite constatar que el contenido del discurso es dinámico, y varía en función de los actores, las épocas y los espacios en los cuales se constituye. Así, si bien hay documentos hitos que definen las prioridades internacionales en la materia, como puede ser el Plan de acción de Beijing, estas cambian, se transforman y adaptan a las realidades y preocupaciones que portan los actores intervinientes en la elaboración de los documentos que suceden la declaración en contextos locales que amplían el concepto de mujer e incluyen situaciones de mujeres afro, indígenas, entre otras, o las condiciones de las mujeres en medio del conflicto, por ejemplo. De esta forma, si bien los conceptos propios de la discusión de los derechos de las mujeres se comparten, en general, en la mayoría de los tres escenarios internacionales analizados, la prioridad de cada uno resulta diversa en función del espacio de discusión.

A su vez, en el nivel local, en Colombia, el contenido y las prioridades del discurso que da cuenta del referencial dominante tampoco son estáticos e inspiran una permanente adecuación y modificación del sentido y, en especial, 
mecanismos o medios destinados a configurar una respuesta estatal en la materia. Así, se puede constatar que el discurso internacional adquiere dimensiones muy específicas en el nivel territorial. Este, si bien retoma las preocupaciones internacionales, adapta y adopta respuestas desde la capacidad local que incluyen tanto las visiones, los valores, el contexto y la realidad sociopolítica nacional reiterando una vez más que la definición de la acción pública es resultado de un proceso de deconstrucción y reconstrucción de la comprensión de las realidades que los actores proyectan y que este proceso es dinámico en la medida en que recoge las versátiles subjetividades de sus portadores.

\section{REFERENCIAS}

Alta Consejería Presidencial para la Equidad de la Mujer (2012). Informe al Congreso de la República. Implementación de la ley 1257 de 2008 por el derecho de las mujeres a vivir sin violencias. Bogotá: СРEM.

Alta Consejería Presidencial para la Equidad de la Mujer (2013). Informe al Congreso de la República. Seguimiento a la implementación de la ley. Bogotá: CPEM.

Alta Consejería Presidencial para la Equidad de la Mujer (2014). Informe al Congreso de la República. Seguimiento a la implementación de la Ley 1257 de 2008. Bogotá: CPEM.

Álvarez, S. (1997). Articulación y transnacionalización de los feminismos latinoamericanos. Debate Feminista, 15 (8), pp. 146-170.

CEDAW (1987). Informe del Comité para la Eliminación de la Discriminación contra la Mujer. $6^{\circ}$ período de sesiones. Asamblea General. Documentos Oficiales. Cuadragésimo segundo período de sesiones Suplemento No. 38 (A/42138).

CEDAW (1993). Examen de los informes presentados por los Estados partes con arreglo al art. 18 de la Convención. Presentación conjunta de los informes periódicos segundo y tercero, revisados, de los Estados partes. COLOMBIA. CEDAW/C/ COL/2-3/Rev. 1

CEDAW (1994). Informe del Comité para la Eliminación de la Discriminación contra la Mujer. $13^{\circ}$ periodo de sesiones. Asamblea General. Documentos Oficiales. Cuadragésimo noveno periodo de sesiones Suplemento No. 38 (A/49/38).

CEDAW (1996). Informe del Comité para la Eliminación de la Discriminación contra la Mujer. $14^{\circ}$ periodo de sesiones. Asamblea General. Documentos Oficiales. Quincuagésimo periodo de sesiones Suplemento No. 38 (A/50/38).

CEDAW (1997). Examen de los informes presentados por los Estados partes con arreglo al art. 18 de la Convención. Cuartos informes periódicos de los Estados partes. COLOMBIA. CEDAW/C/ $\mathrm{COL} / 4$

CEDAW (1999). Observaciones finales del Comité para la Eliminación de la Discriminación contra la Mujer: Colombia. 04/02/99. A/54/38, paras. 337401. (Concluding Observations/Comments). CEDAW (2007). Observaciones finales del Comité para la Eliminación de la Discriminación contra la Mujer: Colombia. CEDAW /C/COL/CO/6.

CEDAW (2013). Observaciones finales sobre los informes periódicos séptimo y octavo combinados de Colombia. CEDAW /C/COL/CO/7-8.

CEDAW (s.f.). Informes periódicos quinto y sexto combinados de los Estados partes. Colombia.

CEPAL (1991). Informe de la quinta conferencia regional sobre la integración de la mujer en el desarrollo 
económico y social de América Latina y el Caribe. LC/G.1684 (CRM.5/6). Curazao: CEPAL.

CEPAL (1994). Informe de la sexta conferencia regional sobre la integración de la mujer en el desarrollo económico y social de América Latina y el Caribe. LC/G.1850(CRM.6/7). Mar de Plata: CEPAL. CEPAL (1997). Informe de la décima conferencia regional sobre la integración de la mujer en el desarrollo económico y social de América Latina y el Caribe. LC/G.2361(CRM.10/8). Quito: CEPAL.

CEPAL (1997). Informe de la décima conferencia regional sobre la integración de la mujer en el desarrollo económico y social de América Latina y el Caribe. LC/G.2361(CRM.10/8). Quito: CEPAL

CEPAL (1997). Informe de la duodécima conferencia regional sobre la integración de la mujer en el desarrollo económico y social de América Latina y el Caribe. LC/L.3789

CEPAL (1997). Informe de la novena conferencia regional sobre la integración de la mujer en el desarrollo económico y social de América Latina y el Caribe. LC/G.2256(CRM.9/6). México: CEPAL

CEPAL (1997). Informe de la octava conferencia regional sobre la integración de la mujer en el desarrollo económico y social de América Latina y el Caribe. LC/G.2087(CRM.8/6). Lima: CEPAL

CEPAL (1997). Informe de la séptima conferencia regional sobre la integración de la mujer en el desarrollo económico y social de América Latina y el Caribe. LC/G.2016 (CRM. 7/7). Santiago de Chile: CEPAL.

CEPAL (1997). Informe de la undécima conferencia regional sobre la integración de la mujer en el desarrollo económico y social de América Latina y el Caribe. LC/L.3309. Brasilia: CEPAL

Cobo, R. (1995). Género. En Aromós (dir). 10 palabras clave sobre mujer. España: Verbo Divino.
Comisión Interamericana de Mujeres (2004). Informe Nacional: Colombia. Washington, D.C.: OEA. OEA/Ser.L/II.2.32 CIM/doc.20/04.

Comisión Interamericana de Mujeres (2006). Informe Nacional: Colombia Item 3 c) on the Agenda. San Salvador: OEA. OEA/Ser.L/II.2.33 CIM/ doc. $23 / 06$.

Comisión Interamericana de Mujeres (2008). Informe Nacional: Colombia Punto 3 b) del temario. Santiago de Chile: oEA. OEA/Ser.L/II.2.34 CIM/doc.26/08.

Comisión Interamericana de Mujeres (2010). Informe Nacional: Colombia Punto 3 b) del temario. México D.F.: oEA. OEA/Ser.L/II.2.35 CIM/ doc. $24 / 10$.

CONPES 140 (2011). Modificación a CONPES social 91 del 14 de junio de 2005: "Metas y estrategias de Colombia para el logro de los objetivos de desarrollo del milenio-2015”. Bogotá: Departamento nacional de planeación.

CONPES 147 (2012). Lineamientos para el desarrollo de una estrategia para la prevención del embarazo en la adolescencia y la promoción de proyectos de vida para los niños, nińas, adolescentes y jóvenes en edades entre 6 y 19 años. Bogotá: Departamento nacional de planeación.

CONPES 161 (2013). Política de equidad de género para las mujeres. Bogotá: Departamento nacional de planeación.

CONPES 2626 (1992). Política social para los jóvenes y las mujeres. Bogotá: Departamento nacional de planeación.

CONPES 2726 (1994). Política de participación y equidad para la mujer. Bogotá: Departamento nacional de planeación.

COnpes 2941 (1997). Avances y ajustes de la Política de participación y equidad para la mujer. Bogotá: Departamento nacional de planeación. 
CONPES 3077 (2000). Política nacional para la construcción de paz y convivencia familiar - Haz paz. Bogotá: Departamento Nacional de Planeación. CONPES 3784 (2013). Lineamientos de política pública para la prevención de riesgos, la protección y garantía de los derechos de las mujeres víctimas del conflicto armado. Bogotá: Departamento nacional de planeación.

Consejería para la equidad de la Mujer (2010a). Informe al Congreso de la República ley 1257 de 2008. Bogotá.

Consejería para la equidad de la Mujer (2010b). Informe al Congreso de la República Ley 1257 de 2008. Bogotá.

Consejería Presidencial para la Equidad de la Mujer y Colegio de Abogados de Madrid (2003). Plan estratégico para la defensa de los derechos de la mujer ante la justicia en Colombia. s. d.

Consejería Presidencial para la Equidad de la Mujer (1999). Plan de Igualdad de oportunidades para las mujeres. Bases del Plan y Plan Básico 2000-2002. Bogotá: Presidencia de la República.

Consejería Presidencial para la Equidad de la Mujer (2003). Mujeres constructoras de paz y desarrollo. Una politica nacional orientada a la paz, la equidad y la igualdad de oportunidades. Bogotá: Presidencia de la República.

Consejería Presidencial para la juventud, la mujer y la familia (1994). Informe de gestión 1990-1994. Bogotá: Presidencia de la República.

Decreto 1182 (1999). Por el cual se modifica la estructura orgánica del Departamento Administrativo de la Presidencia de la República. Bogotá: Presidencia de la República de Colombia.

Decreto 127 (2001). Por el cual se crean las Consejerías y Programas Presidenciales en el Departamento Administrativo de la Presidencia de la República. Bogotá: Presidencia de la República de Colom- bia. Recuperado de https://www.cancilleria. gov.co/sites/default/files/Normograma/docs/ decreto_0127_2001.htm

Decreto 1440 (1995). Por el cual se define y organiza la estructura y funciones de la Dirección Nacional para la Equidad de la Mujer. Bogotá: Presidencia de la República de Colombia. Recuperado de: http://www.icbf.gov.co/cargues/avance/docs/ decreto_1440_1995.htm

Decreto 1649 (2014). Por el cual se modifica la estructura del Departamento Administrativo de la Presidencia de la República. Bogotá: Presidencia de la República de Colombia. Recuperado de http://wsp.presidencia.gov.co/Normativa/Decretos/2014/Documents/SEPTIEMBRE/02/ DECRETO\%201649\%20DEL\%2002\%20 DE\%20SEPTIEMBRE\%20DE\%202014.pdf

Decreto 1930 (2013). Por el cual se adopta la Política Pública Nacional de Equidad de Género y se crea una Comisión Intersectorial para su implementación. Bogotá: Presidencia de la República de Colombia. Recuperado de http://www.icbf.gov.co/ cargues/avance/docs/decreto_1930_2013.htm

Decreto 2055 (1994). Por el cual se crea la Comisión Asesora para la equidad y la participación de la mujer. Bogotá: Presidencia de la República de Colombia. Recuperado de http://www.icbf.gov. co/cargues/avance/docs/decreto_2055_1994. htm

Decreto 2200 (1999). Por el cual se dictan normas para el funcionamiento de la Consejería Presidencial para la Equidad de la Mujer del Departamento Administrativo de la Presidencia de la República. Bogotá: Presidencia de la República de Colombia. Recuperado de http://www.alcaldiabogota. gov.co/sisjur/normas/Norma1.jsp?i=5364

Decreto 3445 (2010). Por el cual se crean unas Altas Consejerías en el Departamento Administrativo 
de la Presidencia de la República. Bogotá: Presidencia de la República de Colombia. Recuperado de http://www.cepal.org/oig/doc/LeyesMAM/ COL/2010_D3445_COL.pdf

Decreto 519 (2003). Por el cual se suprimen, se transforman y se crean unas consejerías y programas presidenciales. Bogotá: Presidencia de la República de Colombia. Recuperado de: http://www. vicepresidencia.gov.co/Programas/Documents/ DECRETO_519_2003.pdf

DNP (1991). La revolución pacifica. Plan de desarrollo económico y social 1990-1994. Bogotá: DNP.

Facio, A. (s.f.). Igualdad o equidad. Nota para la igualdad $N^{\circ} 1$. Politicas que transforman. Una agenda de género para América Latina. Recuperado de: http://www.americalatinagenera.org/es/ documentos/centro_gobierno/FACT-SHEET1-DQEH2707.pdf

Fontaine, G. (2016). El análisis de políticas públicas: conceptos, teorías y métodos. Barcelona y Quito: Anthropos y FLACSO.

García Prince, E. (2008). Políticas de igualdad, equidad y gender mainstreaming. ¿De qué estamos hablando? Marco conceptual. PNUD: Agencia Catalana de Cooperación al Desarrollo, Fondo Español.

Gouin, R. (2012). The uses of cognition in policy analysis: a first appraisal. Journal of Public Administration and Governance, 2 (1). Doi https:// doi.org/10.5296/jpag.v2i1.978

Guzmán Barcos, V. y Montaño Virreira, S. (2012). Políticas públicas e institucionalidad de género en América Latina (1985-2010). En Serie Mujeres y Desarrollo 118. Santiago de Chile: División de Asuntos de Género, CEPAL - Naciones Unidas.

Guzmán Barcos, V. (2003). Gobernabilidad democrática y género, una articulación posible. En Serie Mujeres y Desarrollo 48. Santiago de Chile: División de Asuntos de Género, CEPAL-Naciones Unidas.
Lamas M. (1999). Usos, dificultades y posibilidades de la categoría género. Papeles de Población (021), 147-178.

Montoya Ruiz, A. M. (2009). Recorrido por las políticas públicas de equidad de género en Colombia y aproximación a la experiencia de participación femenina con miras a la construcción de escenarios locales. Estudios de Derecho, LXVI (147), 305-319.

Moser, C. (1998). Planificación de género. Objetivos y obstáculos. En Largo, E. (ed.). Género en el Estado. Estado del Género. Chile: Ediciones de la Mujeres.

Muller, P. (2005). Esquisse d'une théorie du changement dans l'action publique. Structures, acteurs et cadres cognitifs. Revue française de science politique, 55 (1), 155-187. Recuperado de https://www. cairn.info/revue-francaise-de-science-politique2005-1-page-155.htm

Muller, P. (2006). Las politicas públicas. Bogotá: Universidad Externado de Colombia.

Panizza, F. y Miorelli, R. (2012). Taking discourse seriously: Discursive institutionalism and poststructuralist discourse theory. Political Studies, 61, 301-318.

Peláez Mejía, M. (2001). La política de género en el Estado colombiano: un camino de conquistas sociales. Tesis Doctoral en Salud Pública. Escuela Nacional de Salud Pública - Fundación Osvaldo CruzFiocruz, Rio de Janeiro, Medellín.

PNUD (s.f.). Estrategia de equidad de género. Bogotá: PNUD.

Puello-Socarrás, J. F. (2007). La dimensión cognitiva en las políticas públicas. Interpelación politológica. Revista ciencia politica, (3), 30-57.

Puyana, Y. (1998). La política integral para la mujer colombiana. Un lenguaje democrático que no 
logró plasmarse en el actuar democrático. Revista de Trabajo social, (1), 80-86.

Sayago, S. (2013). La metodología de los estudios críticos del discurso problemas, posibilidades y desafios. Recuperado de https://giadpatagonia.files.wordpress.com/2014/04/sayago-la-metodologc3adade-los-estudios-crc3adticos-del-discurso 1.pdf

Sayago, S. (2014). El análisis del discurso como técnica de investigación cualitativa y cuantitativa en las ciencias sociales. Cinta de Moebio. Revista de Epistemología de Ciencias Sociales, (49), 1-10. Recuperado de http://www.redalyc.org/articulo. oa?id=1013141700 1

Schmidt, V. (2008). Discursive institutionalism: The explanatory power of ideas and discourse. Annual Review of Political Science, 11, 303-326

Secretario General de las Naciones Unidas (2014). Examen y evaluación de la aplicación de la
Declaración y Plataforma de Acción de Beijing y los resultados del vigésimo tercer periodo extraordinario de sesiones de la Asamblea General. Consejo Económico y Social, Naciones Unidas, E /CN.6/2015/3

Sikkink, K. y Keck, M. (1999). Redes transnacionales de cabildeo e influencia. Murillo, L. (trad.). Foro Internacional, 39 (4 / 158), 404428. Recuperado de http://www.iheal.univparis3.fr/sites/www.iheal.univ-paris3.fr/files/ keck\%20et\%20sikkink\%20DH4JX1CQXQR8HHPAU9GHG569Q6MVYN.pdf

Surel, Y. (2011). The role of cognitive and normative frames in policy making. Journal of European Public Policy, 7 (4), 495-512. Doi: 10.1080/13501760050165334. 